\title{
The 1999 BDA Heathrow Timings
} inquiry

\author{
Andy Bearne, 'Anthony Kravitz, ${ }^{2}$
}

\begin{abstract}
In the summer of 1999 the BDA conducted a Timings Inquiry in order to provide information on treatment timings within the General Dental Services (GDS) and to develop a model of an hourly rate for general practice. A panel of dentists measured the absolute time taken to carry out 21 key treatments. The relative times of related treatments were then estimated. The panel also came to consensus about the variables to construct the hourly rate model. The absolute timings exercise was applied to the hourly rate model in order to draw some conclusions about the average earnings of a full-time dentist committed to the NHS. This information formed a central part of the BDA's 1999 evidence to the Doctors and Dentists Review Body.
\end{abstract}

Since 1980 a panel inquiry method has Sbeen used to determine a structure of the timings of the over 300 treatments paid by fees in the General Dental Services (GDS). ${ }^{1}$ These timings have been carried out using a relative timings method (relativities) based on the absolute timing of one key item in the Statement of Dental Remuneration (SDR). The first such exercise took place in Sunningdale in 1980, then Keele in 1985, Windermere in 1988, and again in Windermere in 1991, but the results of the 1991 study were never incorporated into the feescale. So the current feescale is still based on the results of the inquiry in 1988. Since then, there have been fundamental changes to the GDS, both in terms of regulations and treatment items in the SDR. Furthermore, the Doctors and Dentists Review Body (DDRB) have been asking the BDA and the Health Departments to carry out a new exercise in order to inform their deliberations.

\footnotetext{
Aims

The GDSC decided to carry out a new Inquiry, during the summer of 1999. The Timings Inquiry had two primary aims. The first aim was to examine the structure of timings within the SDR. The second aim

${ }^{1}$ Economist, ${ }^{2}$ Chairman of the GDSC, British Dental Association, 64 Wimpole Street, London, W1M 8AL REFEREED PAPER

Received 12.10.99; ACCEPTED 13.12.99

(c) British Dental Journal 2000; 188: 186-194
}

was to develop a model of an hourly rate for general dental practice. This could then be used in conjunction with the information gathered on timings to inform the debate concerning the earnings of an average dentist committed to the NHS. This is an area in which the DDRB had sought agreement between the BDA and the Health Departments.

\section{Inquiry method}

Selection of panel members

The inquiry was conducted by a panel of dentists from various BDA committees. They were chosen to reflect the profession in terms of gender, geography and age, and were in active practice, predominantly in the GDS. A working party produced a list of 18 potential panel members who subsequently attended a half-day training session. Between the training day and the main exercise two potential panel members dropped out, leaving a panel of 16 . Table 1 shows that the panel was representative of the overall profession in terms of age and gender. Figure 1 shows that representation of panel members was reasonably geographically spread.

The training exercise

The training exercise was held at BDA headquarters on June 10th, 1999 where it was explained that the fee scale is split into groups, or 'families', the following of which were to be included in the exercise:

\section{In brief}

- This paper shows that on average dentist with a reasonable commitment to the GDS works 43.5 hours per week. They have 4.5 weeks holiday a year. Taking account of sickness and bank holidays, this leaves 1953 hours of working time available in a year. Of this, 405 hours are spent on administration (including post graduate education), leaving 1548 hours of clinical time (excluding time spent on call).

- A dentist committed to the NHS had average net earnings after expenses of around $£ 46,700$ in $1998 / 99$. The hourly rate required to achieve this is around £47.

- The absolute time taken for a range of treatments lends credibility to this hourly rate and net earnings figure.

- The majority of relative timings within the fee scale appear to be about right but there are some anomalies.

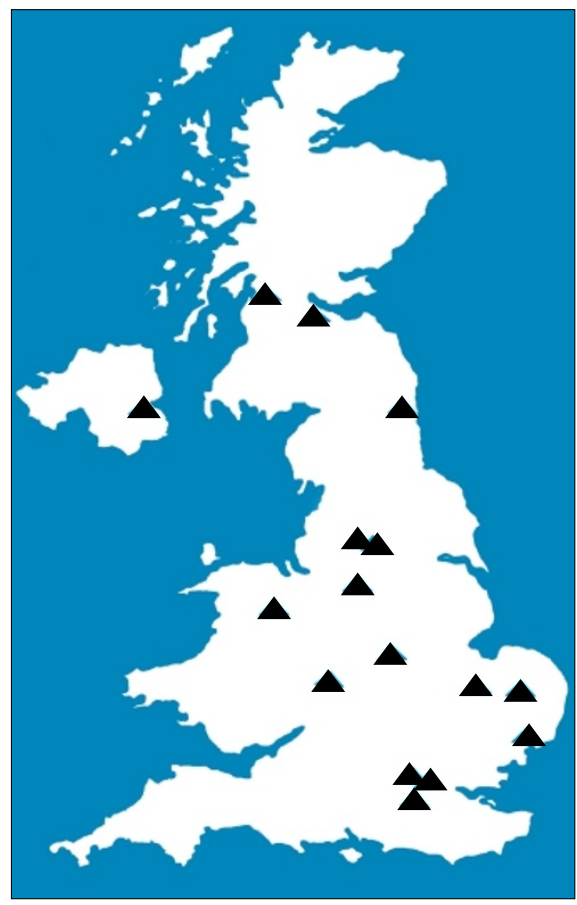

Fig. 1 Map showing geographical location of panel members 


\begin{tabular}{|lccc|}
\hline Table 1 & & & \\
& & & \\
& Per cent of GDS dentists & Per cent of panel & Number of panel \\
Male under 40 & $33 \%$ & $31 \%$ & 5 \\
Female under 40 & $19 \%$ & $12.5 \%$ & 2 \\
Male $40+$ & $39 \%$ & $44 \%$ & 7 \\
Female 40+ & $9 \%$ & $12.5 \%$ & 2 \\
Male overall & $72 \%$ & $75 \%$ & 12 \\
Female overall & $28 \%$ & $25 \%$ & 4 \\
Total & - & - & 16 \\
\hline
\end{tabular}

Table 2 Absolute timings resulis

\begin{tabular}{|c|c|c|c|c|c|}
\hline \multirow[b]{2}{*}{ Treatment } & \multicolumn{3}{|c|}{ Average time (minutes) } & \multicolumn{2}{|c|}{ Standard deviation } \\
\hline & $\begin{array}{l}\text { Initial } \\
\text { estimate }\end{array}$ & $\begin{array}{l}\text { Final estimate } \\
\text { following group } \\
\text { discussions }\end{array}$ & Change & $\begin{array}{l}\text { Initial } \\
\text { estimate }\end{array}$ & $\begin{array}{l}\text { Final } \\
\text { estimate }\end{array}$ \\
\hline Clinical exam and report & 10.1 & 11.3 & 1.2 & 1.76 & 2.31 \\
\hline Full case assessment & 21.6 & 25.0 & 3.4 & 6.23 & 8.62 \\
\hline Small intraoral radiograph & 6.3 & 8.9 & 2.6 & 3.93 & 2.94 \\
\hline Simple scaling & 14.2 & 15.1 & 1.0 & 2.81 & 3.07 \\
\hline Chronic periodontal, $1-4$ teeth & 33.3 & 50.8 & 17.6 & 20.42 & 15.51 \\
\hline MO or DO amalgam filling & 18.3 & 19.7 & 1.4 & 3.22 & 2.94 \\
\hline Composite filling & 17.8 & 20.9 & 3.1 & 4.48 & 4.44 \\
\hline Lower premolar root filling & 40.0 & 49.4 & 9.4 & 9.64 & 12.87 \\
\hline Molar root filling & 67.4 & 75.7 & 8.3 & 13.36 & 12.57 \\
\hline Porcelain veneer & 50.2 & 50.5 & 0.3 & 18.88 & 16.16 \\
\hline Precious metal bonded crown & 59.6 & 63.7 & 4.1 & 18.88 & 14.06 \\
\hline Refixing a crown & 12.2 & 13.2 & 0.9 & 3.54 & 2.93 \\
\hline Extraction of 1 tooth & 15.6 & 17.6 & 2.0 & 5.01 & 3.41 \\
\hline $\begin{array}{l}\text { Complete dentures, } \\
\text { without special trays }\end{array}$ & 63.0 & 76.4 & 13.3 & 15.81 & 15.77 \\
\hline \multicolumn{6}{|c|}{ Metal partial denture, skeleton } \\
\hline design $4-8$ teeth & 64.7 & 79.1 & 14.3 & 19.23 & 19.30 \\
\hline Dentures: addition of a tooth & 18.8 & 20.9 & 2.1 & 5.75 & 4.59 \\
\hline $\begin{array}{l}\text { Recalled attendance } \\
\text { more than } 1 \text { mile }\end{array}$ & 66.2 & 66.9 & 0.6 & 24.09 & 19.88 \\
\hline Deciduous teeth: 1 filling & 16.2 & 17.6 & 1.4 & 5.24 & 4.81 \\
\hline Composite resin restoration & 14.4 & 18.2 & 3.9 & 5.92 & 4.00 \\
\hline Under 12 years extraction & 17.2 & 17.5 & 0.3 & 5.97 & 4.50 \\
\hline Treatment of acute conditions & 9.8 & 10.2 & 0.4 & 2.12 & 1.81 \\
\hline
\end{tabular}

- Examination

- Diagnosis

- Periodontal

- Fillings

- Root fillings

- Veneers and inlays

- Crowns and bridgework

- Extractions

- Dentures

- Repairs and alterations

- Domiciliary/recalled attendance

- Miscellaneous

- Deciduous teeth

Within these families, eight out of the ten items used in previous timings exercises were selected for the absolute timings part of the inquiry (the GDSC had decided that orthodontics and general anaesthesia/sedation should not be included in the current exercise). The panel agreed to add 13 other items, which they believed should be timed absolutely - the final list is shown in Table 2.

It was explained that an actual, or 'absolute' time would be calculated for each of the key items. The panel would then consider each other item within the family in relation to the key item, and produce a relative timing.

For the absolute timings part of the exercise the panel was asked to split key treatment items into three parts and to determine how much time is spent on each element:

- Time taken for the patient to enter and to leave the surgery.

- Where appropriate, the time taken to administer a local anaesthetic.

- Time taken to carry out the treatment.

They were asked to assume that they carried out all treatments themselves, rather than delegating to a professional complementary to dentistry. For items such as fillings and crowns, they were asked to consider these as if they were done as a single item, rather than as two or more on the same visit. Likewise, the timing of a scaling and polishing was to be considered as a standalone, although it was appreciated that this was often not the case. However, it was emphasised that estimates should relate to whatever they considered to be normal circumstances of work in providing each treatment item. If they thought of other special considerations, then they were asked to tell the panel and let the other members take them into account too. The panel were given data sheets and asked to consider and record

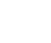

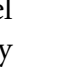


 general practice}

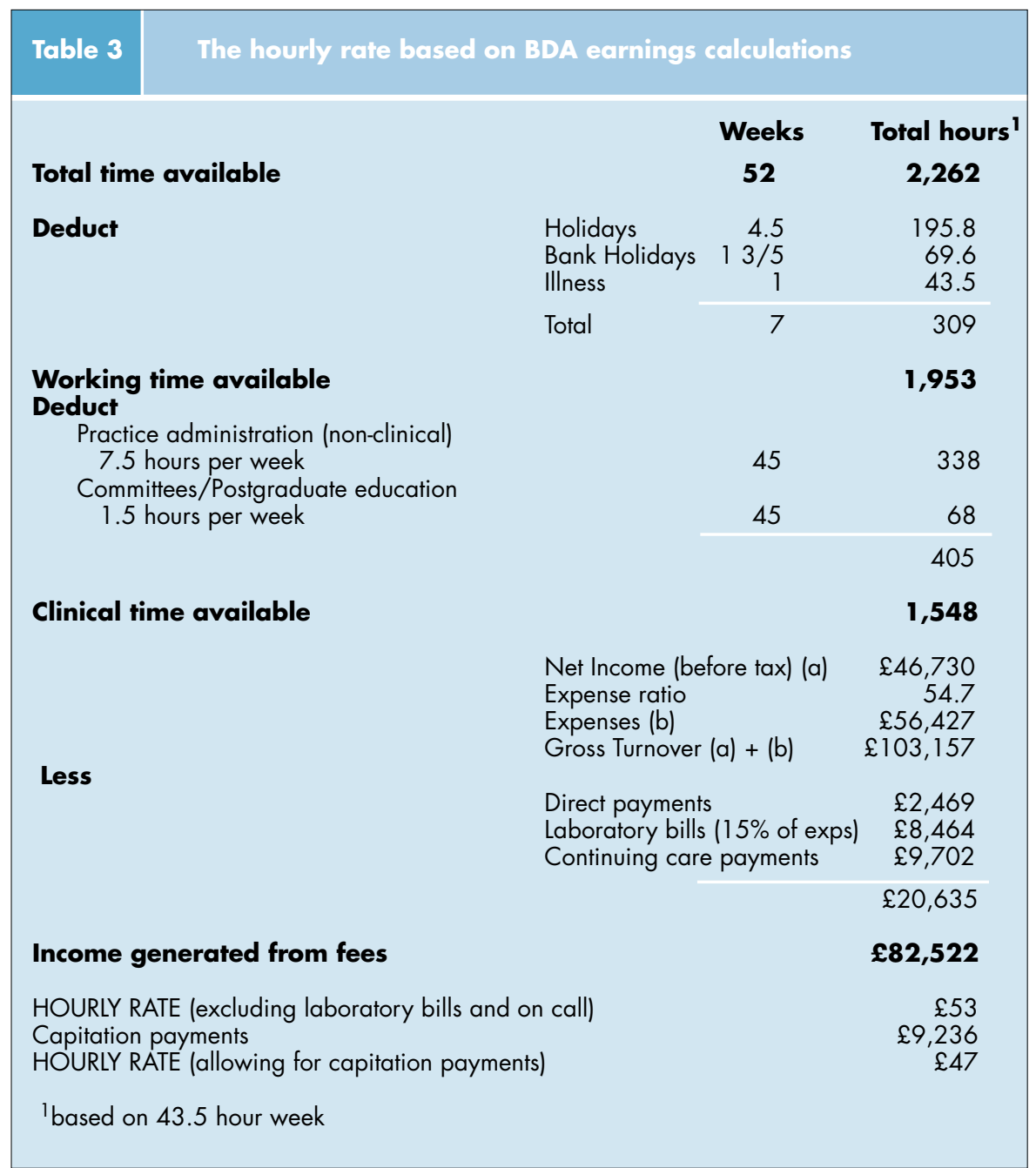

their personal timings in their own practices on the 21 key items in Table 2.

The actual event

The main exercise was held at a hotel in
Heathrow, London on July 6th and 7th 1999. In addition to the 16 panel members, two observers from the secretariat to the DDRB, the Office of Manpower Economics, two observers from the Department of
Health, and two statisticians from the BDA secretariat attended. The event proceeded as described in Figure 2.

For the relative timings part of the exercise the panel was split into three groups and given sheets showing current relative time values between associated items in the family groups. Each group was given a set of family treatments to consider. Where groups had spare time they moved on to the families being considered by other groups.

\section{Results and Analysis}

The working week

The panel decided that a normal full-time working week for a general dental practitioner (GDP) consists of 43.5 hours. They also decided that four and a half weeks would be spent on holidays (in addition to bank holidays) and that GDPs lose on average one week a year from illness. This leaves 45 weeks available for work, giving a total number of hours of work per annum of 1,953 . It was agreed that time spent oncall should be ignored as this was too variable. Continuing Care payments (CCPs) and a continuing care element of capitation payments would also be excluded

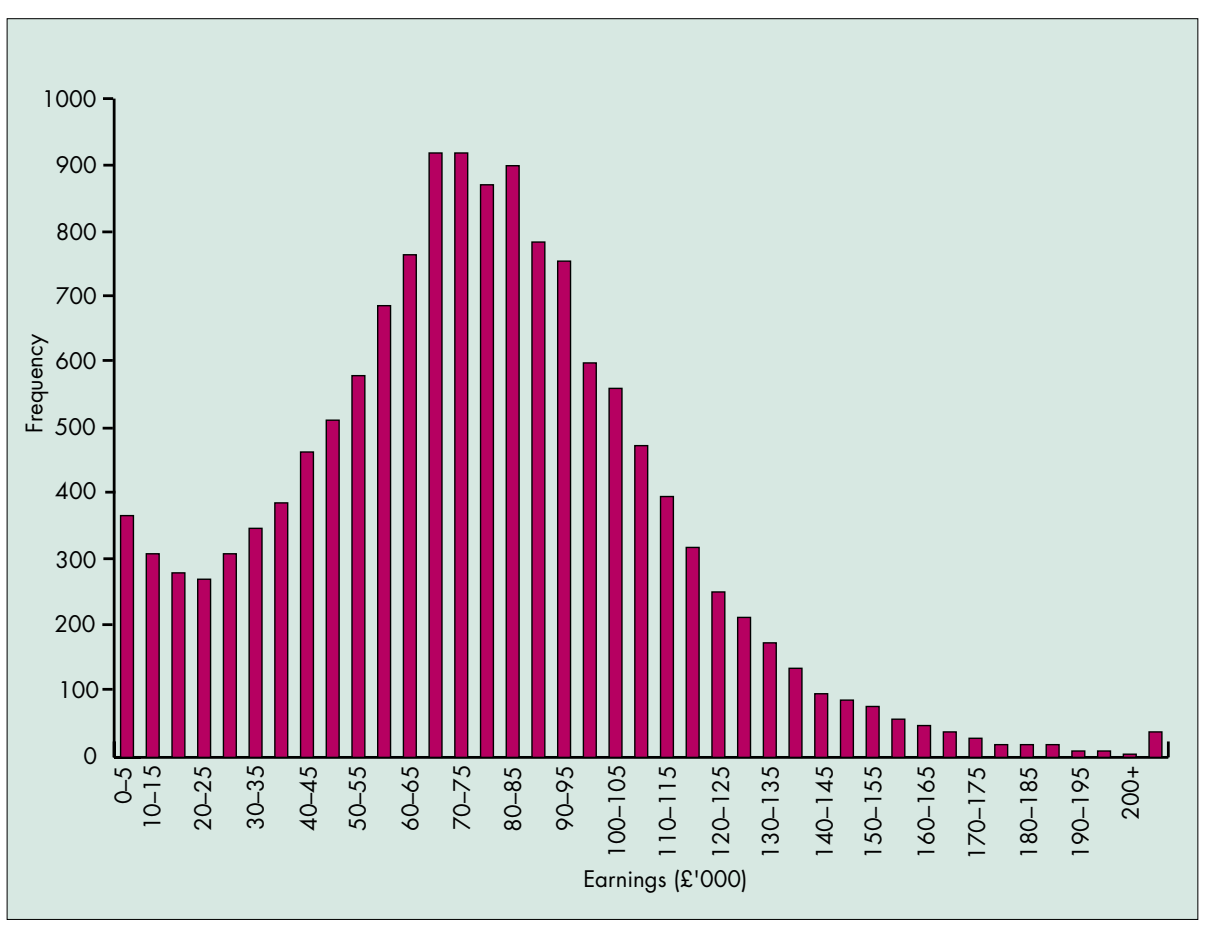




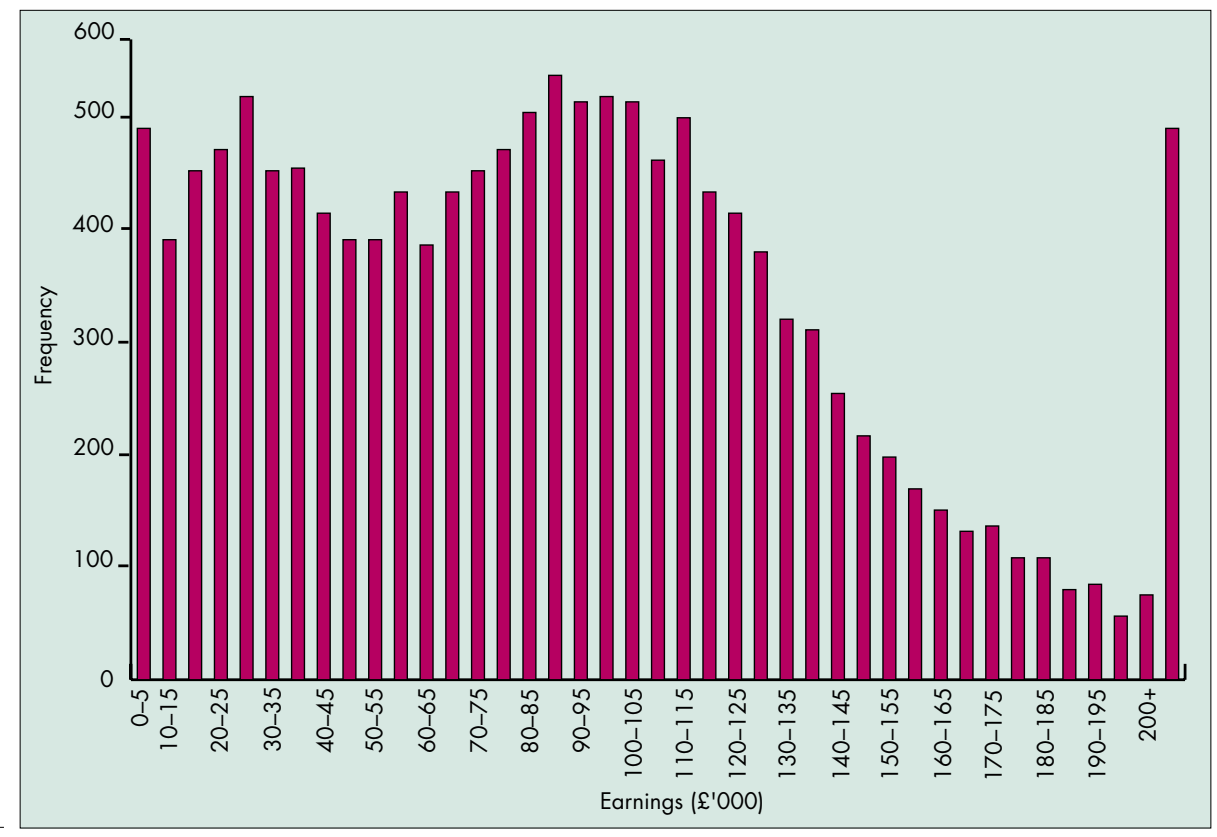

Fig. 4 DRSG earnings distribution England and Wales 1997/98

from the income calculations, as the panel felt that essentially CCPs paid for this oncall work.

Taking the balance between first and second party associates, partners and singlehanded GDPs, the panel concluded that around seven and a half hours per week is spent on administration. Also around one and a half hours is spent on postgraduate

\section{Expenses}

An expenses ratio of $54.7 \%$ of turnover was used, as evidenced by the last known Inland Revenue expenses survey. ${ }^{2}$ Fifteen percent of the expenses would be deducted from turnover for laboratory bills, again based on the Inland Revenue survey. Direct payments such as Rates Reimbursement and Seniority Pay would also be deducted from the aver-

\begin{tabular}{|c|c|c|c|c|c|}
\hline Table 4 & \multicolumn{5}{|c|}{$\begin{array}{l}\text { Treatment scenarios based on the April } 1999 \text { fee scale }{ }^{3} \\
\text { and absolute timings }\end{array}$} \\
\hline \multirow{3}{*}{ Example 1} & \multirow{3}{*}{$\begin{array}{l}\text { Patient A } \\
\text { Patient B } \\
\text { Patient C }\end{array}$} & Treatment & Fee & Time taken & Implied hourly \\
\hline & & \multirow[t]{2}{*}{$\begin{array}{l}\text { Exam, } 2 \text { radiographs } \\
2 \text { surface metal filling } \\
\text { Molar root filling* }\end{array}$} & $\begin{array}{l}£ 10.05 \\
£ 12.40 \\
£ 35.00\end{array}$ & $\begin{array}{l}15 \text { mins } \\
18 \text { mins } \\
40 \text { mins }\end{array}$ & \\
\hline & & & $£ 57.45$ & 73 mins & $£ 47.22$ \\
\hline \multirow[t]{2}{*}{ Example 2} & \multirow[t]{2}{*}{$\begin{array}{l}\text { Patient D } \\
\text { Patient E }\end{array}$} & \multirow[t]{2}{*}{$\begin{array}{l}\text { Exam, scaling } \\
\text { Lower premolar root filling }{ }^{\dagger}\end{array}$} & $\begin{array}{l}£ 15.35 \\
£ 35.50\end{array}$ & $\begin{array}{l}20 \text { mins } \\
52 \text { mins }\end{array}$ & \\
\hline & & & $£ 50.85$ & 72 Mins & $£ 42.38$ \\
\hline \multirow[t]{2}{*}{ Example 3} & \multirow[t]{2}{*}{$\begin{array}{l}\text { Patient F } \\
\text { Patient G } \\
\text { Patient H }\end{array}$} & \multirow[t]{2}{*}{$\begin{array}{l}\text { Two white fillings } \\
\text { One extraction } \\
\text { One deciduous filling }\end{array}$} & $\begin{array}{l}£ 23.90 \\
£ 10.65 \\
£ 5.85\end{array}$ & $\begin{array}{l}30 \text { mins } \\
16 \text { mins } \\
17 \text { mins }\end{array}$ & \\
\hline & & & $£ 40.40$ & 63 mins & $£ 38.48$ \\
\hline $\begin{array}{l}\text { * First visit, } \\
\dagger \text { Including }\end{array}$ & $\begin{array}{l}\text { In includin } \\
\text { e radiogra }\end{array}$ & $\begin{array}{l}\text { g one radiograph. } \\
\text { ph. }\end{array}$ & & & \\
\hline
\end{tabular}

education and committee work. They based this on the assumption that half the profession did these, but for three hours a week. Non-clinical work is therefore 405 hours per annum. This leaves 1,548 hours available for fee earning clinical work. The assumption was made that dentists do not normally work on bank holidays, other than providing out of hours cover. age amount. The part of capitation fees that does not constitute the continuing care element would be for treatment and so needed to be part of the hourly rate.

\section{Average earnings}

The hourly rate model needed an estimate of average earnings. Figures 3 and 4 show how the earnings distribution has changed during the 1990s. In 1990/91 a reasonably standard earnings curve is evident, with a small left-hand tail of low earners followed by a clearly identifiable peak and a long right hand tail. The distribution had changed dramatically by $1997 / 98$. The left-hand tail of low earners grew, the central peak became much less clearly defined, and the right hand tail became increasingly significant. In 1997/98 the distribution is trimodal, although the left hand half of the distribution is fairly flat, calling into question the use of an arithmetic mean, or indeed any other measure of the average for the whole distribution.

First, the distribution may have been distorted by dentists working more part time in the GDS. There are an increasing proportion of female dentists and older dentists, and both of these groups tend to work relatively fewer hours. Part time GDS work also reflects the shift into private practice. The right hand tail also includes dentists who have unusually high NHS earnings and are also unrepresentative of the average dentist committed to the NHS.

The BDA used the following methodology to overcome this problem in its 1999 evidence to the DDRB.

- Remove the data of dentists with gross NHS earnings of less than $\mathfrak{E} 48,000$.

- Remove the data of dentists with gross NHS earnings of more than $£ 180,000$.

- Calculate mean gross NHS earnings of all remaining dentists.

For 1998/99 this gives average gross NHS earnings from fees of $\mathfrak{£} 103,157$ giving a net figure of $\mathfrak{1} 46,730$, after deduction of expenses at $54.7 \%$.

When introduced into the hourly model this gives an hourly rate of $\mathfrak{k} 53$, calculations 
for which are shown in Table 3. It is estimated that in 1998/99 $£ 9,236$ of gross turnover would come from capitation payments after deducting the CCP element. This would reduce the hourly rate from item of service fees by $\mathfrak{E} 6-47$.

The Health Departments use a different set of assumptions to estimate average earnings. In their evidence to the DDRB in November 1999, they estimate net average income from fees to be around $\mathfrak{E} 50,000$, giving corresponding hourly rate figures of $\mathfrak{E} 57$ and $\mathfrak{E} 51$.

\section{Absolute timings}

Table 2 shows the results from the original data sheets and the revised timings in light of the panel's discussions. All timings were revised upwards as a result of the deliberations of the panel. The standard deviation is a measure of the dispersion of the absolute timings and shows the extent to which views converged following discussion. The spread of results narrowed for over three quarters of the treatments measured.

The hourly rate model combined with the absolute timings can be used to draw conclusions about the robustness of the various estimates of average earnings. This is somewhat limited as only treatments with no laboratory charges can be used (this means that the fee is paying solely for the dentist's time and materials used), but it provides some useful indications. Table 4 shows three examples of what a dentist might do within a typical hour, and the related fees. The hourly rate ranges from $\mathfrak{E} 38.48$ to $\mathfrak{E} 47.22$.

\section{Relative timings}

Results are shown in Table 5. It was decided on the day not to include the families for veneers, recalled attendance, deciduous fillings and under- 12 extractions. Where more than one group considered a treatment, an average has been taken. For the bulk of treatments the relativities had not changed much from their 1988 values. Items for which the relative timings had changed significantly are shown in Table 6 . These items have been selected broadly on the basis of a change of $10 \%$ or more, although discretion has been applied for treatments with very low or very high incidences.

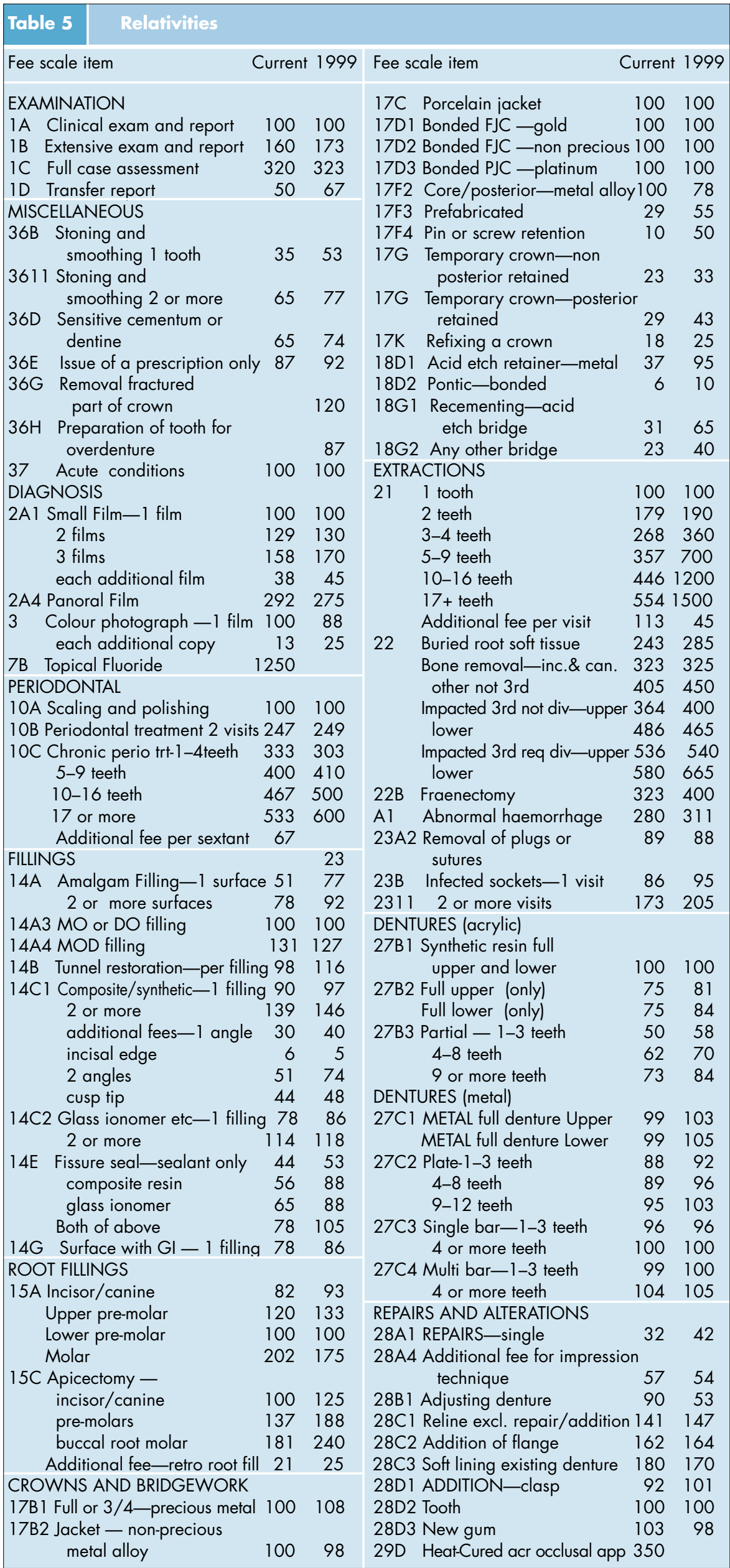




\section{Conclusion}

Using a panel of representative dentists, the 1999 BDA Timings Inquiry had two primary aims. The first was to examine the structure of the timings within the SDR. Changes in fees based on such an exercise have not occurred since 1988 and fundamental changes to the GDS have occurred since then. Whilst many of the relative timings within treatment families have not changed significantly, there have been some notable exceptions. Some of these items appear to be over-imbursed in the feescale and some under-imbursed. The results will be noted by the GDSC and will be used as the basis of future negotiations over the feescale.

The second aim of the Inquiry was to develop a model of an hourly rate for general dental practice and to use this to draw some conclusions about the average earnings of a full-time dentist committed to the NHS. The results of the timings exercise

\begin{tabular}{|c|c|c|c|c|c|}
\hline Table 6 & \multicolumn{5}{|c|}{$\begin{array}{l}\text { Treatments for which relative timings have shifted significantly } \\
\text { since the } 1988 \text { Relativities Inquiry }\end{array}$} \\
\hline \multicolumn{2}{|c|}{ Fee scale item } & $\begin{array}{c}\text { Direction } \\
\text { of change } \\
\text { Up }\end{array}$ & \multicolumn{2}{|c|}{ Fee scale item } & $\begin{array}{l}\text { Direction } \\
\text { of change }\end{array}$ \\
\hline $\begin{array}{l}1 \mathrm{D} \\
2 \\
3 \\
10 \mathrm{C} \\
14 \mathrm{Al} \\
14 \mathrm{~A} 2 \\
14 \mathrm{~B} \\
1422 \\
1424 \\
14 \mathrm{E} \\
15 \mathrm{C} \\
17 \mathrm{~F}\end{array}$ & $\begin{array}{l}\text { Transfer report } \\
\text { Additional radiographs } \\
\text { (after 3) } \\
\text { Colour photographs } \\
\text { Chronic Perio, } 17 \text { or } \\
\text { more teeth } \\
\text { Amalgam Filling-1 surface } \\
\text { Same - } 2 \text { or more surfaces } \\
\text { Tunnel restorations } \\
\text { Composite additional } \\
\text { fees-1 angle } \\
\text { Same-2 angles } \\
\text { Fissure sealant restorations } \\
\text { Apicectomies } \\
\text { Core / post }\end{array}$ & $\begin{array}{l}\text { Up } \\
\text { Down } \\
\text { Down } \\
U_{p} \\
\text { s } U_{p} \\
U_{p}\end{array}$ & $\begin{array}{l}17 F 4 \\
17 G \\
17 K \\
18 D 1 \& D 2 \\
18 G \\
21 \\
22 \\
23 A \\
23 B \\
28 A 1 \\
28 B 1 \\
36 B\end{array}$ & $\begin{array}{l}\text { Pin or screw retention } \\
\text { Temporary crowns } \\
\text { Recementing Crowns } \\
\text { Maryland Bridges } \\
\text { Recementing Bridges } \\
\text { Multiple extractions } \\
\text { (> } 5 \text { teeth) } \\
\text { Surgical Extractions, } \\
\text { lower wisdom teeth } \\
\text { Abnormal haemorrhage } \\
\text { Infected sockets } \\
\text { Denture repairs } \\
\text { Adjusting dentures } \\
\text { Stoning \& smoothing }\end{array}$ & $\begin{array}{l}U p \\
U p \\
U p \\
U p \\
U p \\
U p \\
U p \\
U p \\
U p \\
U p \\
\text { Down } \\
U p\end{array}$ \\
\hline
\end{tabular}

were used to construct three hypothetical scenarios for what treatments a dentist might carry out within an hour. These gave

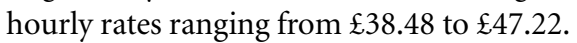
In evidence to the DDRB this year the BDA and the Health Departments estimated average net earnings from fees of $£ 46,730$ and around $\mathfrak{E 5 0 , 0 0 0}$ respectively. This equates to hourly rates of $£ 47$ per hour (after capitation payments are accounted for) for the BDA and $\mathfrak{5} 51$ (ND) for the Health Departments. The BDA's result is much more in line with the results of the hypothetical treatments scenarios. It is suggested that the BDA's estimate of average net earnings in $1998 / 99$ of under $£ 47,000$ is more realistic than the Health Department's

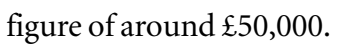

1 Nettley M P, Scarrott D, Windermere Relativities Inquiry, Brit Dent $J, 1988 ; 165$ : 188-192

2 Department of Health. General Dental Practitioners: Supplementary Evidence on Earnings and Expenses for the year 1997/98: Initial Analysis; Department of Health, 1999.

3 Statement of Dental Remuneration, Number 83, Department of Health, London. 